\title{
TRATAMENTUL CU BIFOSFONAȚI ÎN OSTEOGENESIS IMPERFECTA LA COPIL
}

\author{
Alina Murgu ${ }^{1}$, Roxana Crețu ${ }^{2}$, Adnana Jaramani², Elena Macsim³, \\ Ana Maria Chiforeanu ${ }^{2}$ \\ ${ }^{1}$ Clinica 2 Pediatrie, Spitalul Clinic de Urgențe ,Sf. Maria“, \\ Universitatea de Medicină şi Farmacie „, Gr. T. Popa“, Iaşi \\ ${ }^{2}$ Secția Ortopedie Pediatrică, Spitalul Clinic de Urgențe ,, Sf. Maria “, Iaşi \\ ${ }^{3}$ Secția Radiologie, Spitalul Clinic de Urgențe ,, Sf. Maria“, Iaşi
}

\begin{abstract}
Osteogenesis imperfecta $(\mathrm{OI})$ reprezintă un grup de tulburări rare, congenitale, ale țesutului conjunctiv, caracterizate în principal prin fragilitate osoasă importantă, tulburări cauzate de mutații ale colagenului. Prezentăm comparativ cazul a 2 pacienți diagnosticați cu diferite tipuri de OI. Scopul studiului a fost de a compara eficiența tratamentului cu bifosfonați asociat tratamentului chirurgical al fracturilor cu impact asupra calității vieții bolnavului.
\end{abstract}

Cuvinte cheie: osteogenesis imperfecta, bifosfonați, copil

\section{INTRODUCERE}

Osteogenesis imperfecta (OI) reprezintă un grup de tulburări rare, congenitale, ale țesutului conjunctiv, cu transmitere prioritar autozomal dominantă, având ca şi caracteristică comună fragilitatea osoasă excesivă, cauzată de mutații ale colagenului tip I (1), la nivelul genelor alfa 1 şi alfa 2, care codifică lanţurile de procolagen tip I alfa 1 şi respectiv alfa $2(2,3)$.

\section{Cazul 1}

Nou-născut, de sex masculin internat în prima zi de viaţă în secția de chirurgie pentru fractură bilaterală proximală femurală (Fig. 2). A fost născut pe cale naturală, în prezentație craniană, la vârsta gestațională de 38 de săptămâni, cu o greutate la naştere de $3.200 \mathrm{~g}$, cu o adaptare bună la viața extrauterină, fără incidente. Sarcina nu a fost dispensarizată. $\mathrm{Nu}$ a existat istoric de tendință la fracturări în familie şi nici un istoric familial de copil cu fracturi la naştere. Pe durata spitalizării, pacientul a prezentat episoade de fracturi spontane fără deplasare, după mobilizări minime, care au fost tratate conservator folosind imobilizarea segmentelor afectate (Fig. 3): antebrat stâng (Fig. 4), humerus stâng (Fig. 1) şi gambă bilateral (Fig. 2). Examenul clinic şi cel oftalmologic obiectivează aspectul de sclere albastre (Fig. 5).

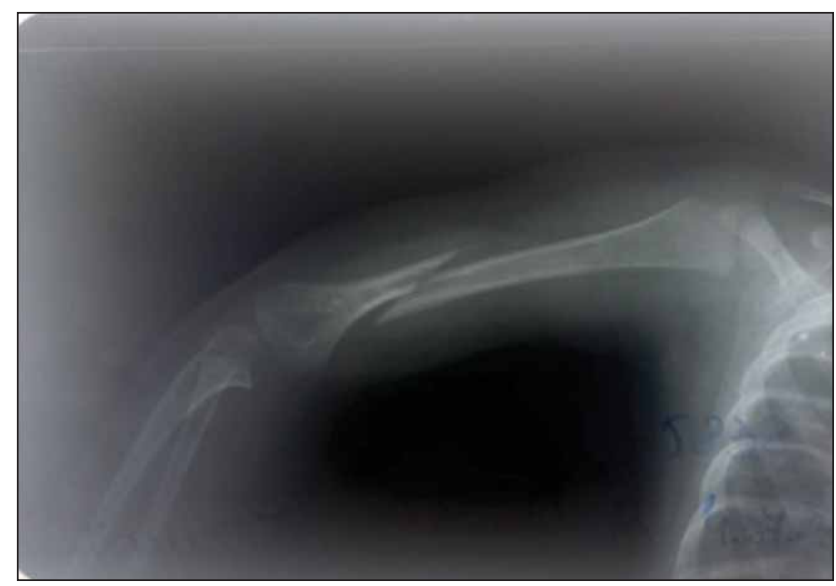

FIGURA 1. Fractură diafizară distală humerus

\section{INVESTIGAṬII}

Ca total $-7,17 \mathrm{mg} / \mathrm{dl}$ (VN: 8,4-11), Ca ionic $4,25 \mathrm{mg} / \mathrm{dl}(4,3-5,3), \mathrm{P}-4,29 \mathrm{mg} / \mathrm{dl}, \mathrm{FA}-691 \mathrm{U} / \mathrm{L}$ 


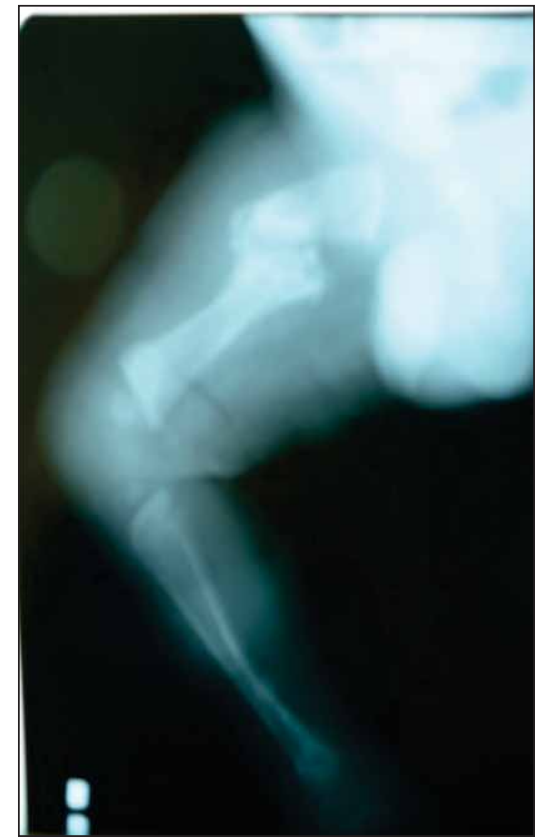

FIGURA 2.

Fractură diafizară femur şi tibie

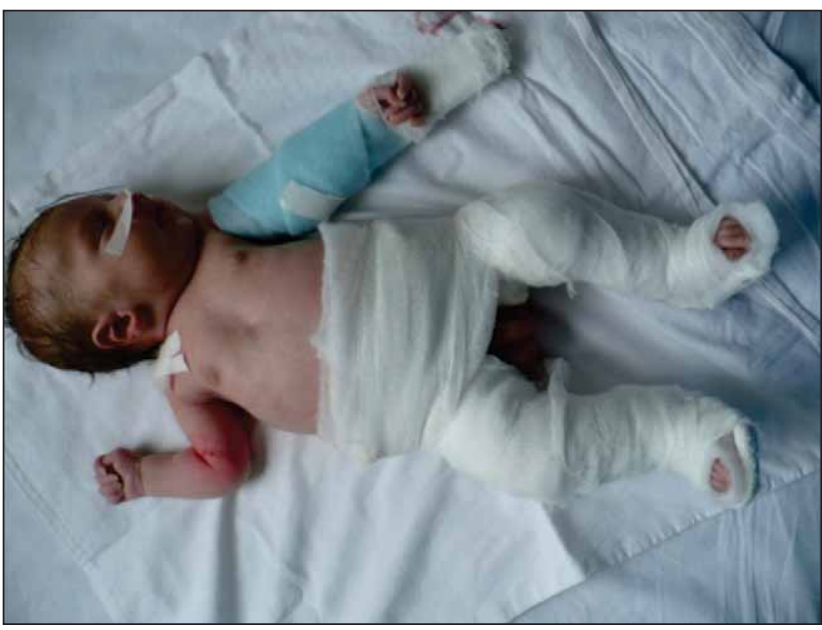

FIGURA 3. Imobilizare gipsată

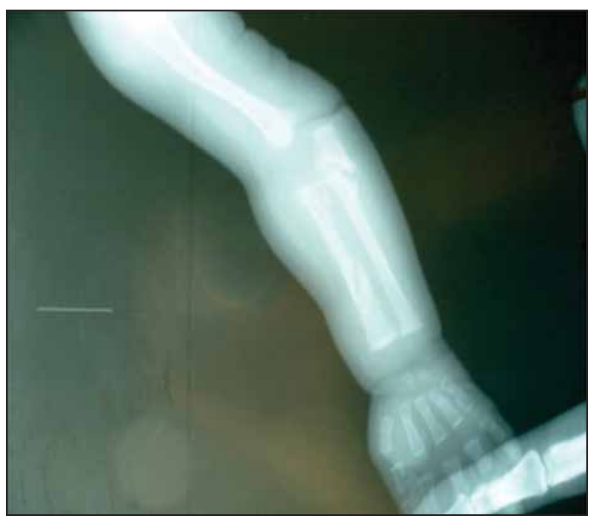

FIGURA 4.

Fractură radius şi olecran

(VN: 40-600), CPK - 238 U/L (VN: 24-225), LDH - $446 \mathrm{U} / \mathrm{L}(\mathrm{VN}: 300-600)$, PTH seric $-22 \mathrm{pg} / \mathrm{ml}$ (15-65), TGP - 18U/L (VN: 5-38), TGO - $46 \mathrm{U} / \mathrm{L}$ (5-35), uree - $25 \mathrm{mg} / \mathrm{dl}(\mathrm{VN}: 10-40)$, creatinina serică $-0,43 \mathrm{mg} / \mathrm{dl}(\mathrm{VN}: 0,4-1,0)$, calciurie $-65,87$ mg/24h (VN: 100-320), creatinina urinară: 57 mg/ dl (VN: 90-300), fosfor urinar: $290 \mathrm{mg} / 24 \mathrm{~h}$ (400-

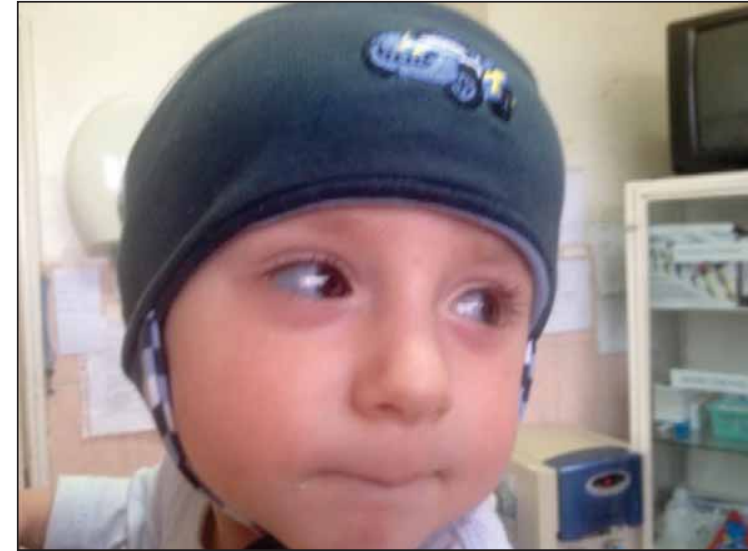

FIGURA 5. Sclere albastre

1300), glicemie $-88 \mathrm{mg} / \mathrm{dl}, \operatorname{IgG}, \operatorname{IgA}, \operatorname{IgM}$ - valori normale, osteocalcin - $28 \mathrm{ng} / \mathrm{ml}$ (24-70), 1,25 $(\mathrm{OH}) 2$ - Vitamina D3 - $45 \mathrm{pg} / \mathrm{ml}$ (VN: 29-100), test boli lizozomale - pentru boala Gaucher negativ, timpanograma, EKG - aspect normal, ecocordiografie - foramen ovale permeabil, osteodensitometrie initiala - scor Z: valori normale.

Examenul genetic a confirmat diagnosticul de osteogenesis imperfecta tip III.

Pacientul a început tratamentul cu un aport regulat de calciu, suplimentar unui aport suficient de vitamina D3.

Până în prezent, la vârsta de 2 ani, pacientul a avut 12 internări, cu un număr total de 21 de fracturi, incluzând 13 fracturi femurale, 4 fracturi tibiale, 2 fracturi de antebraț şi 2 fracturi la nivelul humerusului, mai ales iterative, care au rezultat în urma unor traumatisme minime. Pe durata monitorizării s-a obiectivat radiologic osteoporoză scheletală difuză. În acest caz, terapia cu bifosfonați nu a fost disponibilă, iar tratamentul corect cu calciu şi vitamina D3 a evidențiat efecte reduse asupra ameliorării ratei fracturilor. Pe parcursul monitorizării bolnavul nu a asociat decât rare intercurențe infecțioase respiratorii virale şi un episod de infecție urinară. În evoluție bolnavul prezintă atitudine vicioasă a membrelor afectate, cu deformarea acestora în valgum (Fig. 6,7), important handicap locomotor şi cifoscolioză secundară compensatorie (Fig. 8) deformărilor membrelor inferioare.

\section{Cazul 2}

Pacient de sex masculin, în vârstă de 23 de luni, a fost internat în secția de ortopedie pediatrică pentru o fractură femurală, apărută după un traumatism minor. Anamnestic a prezentat două fracturi de femur (Fig. 10, 11) şi peroneu în ultimele 8 luni, rezultate după mobilizări minime, care au ridicat sus- 

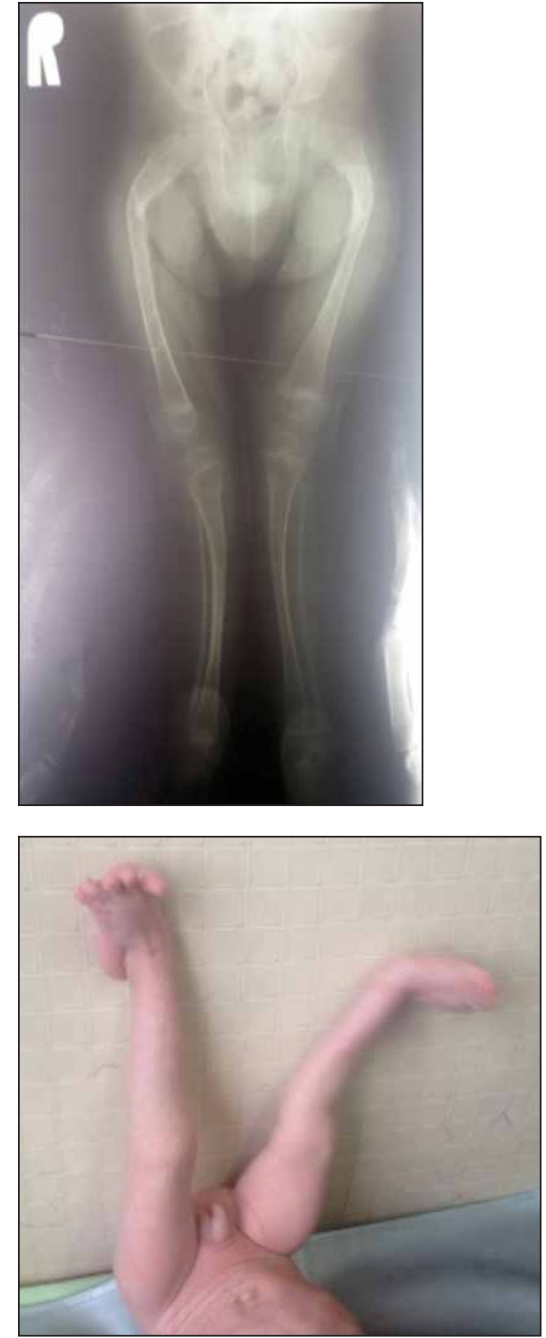

FIGURA 6,7. Deformarea în valgus a membrelor inferioare

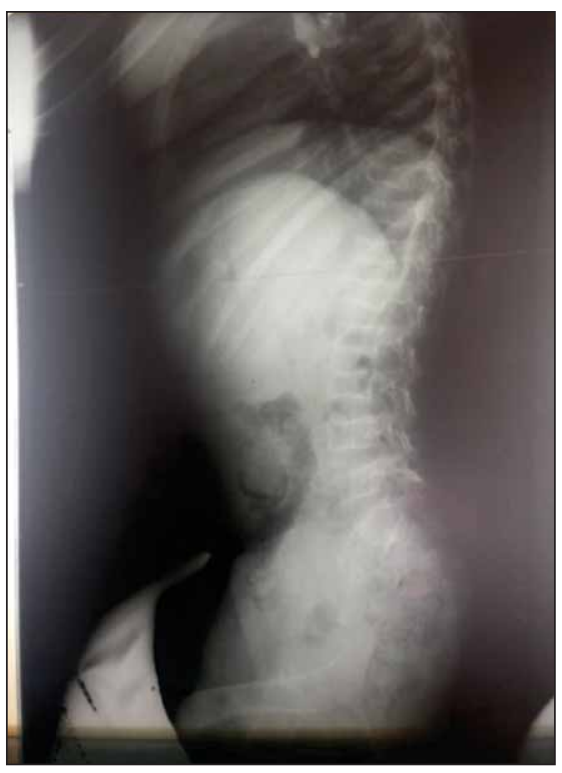

FIGURA 8. Cifoscolioză

piciunea unei afecțiuni osoase. Examenul clinic a evidențiat sclere aparent albastre (Fig. 9).

Este al doilea copil al unui cuplu sănătos (mama -25 de ani, tata -29 de ani), fără istoric intrafamilial

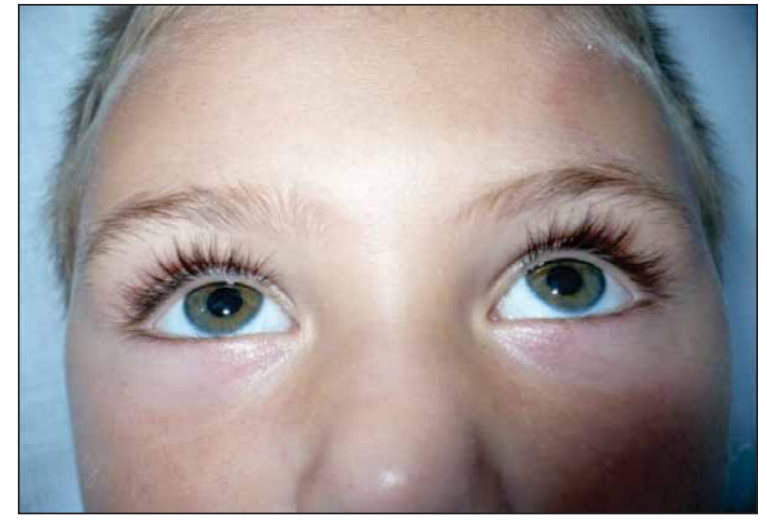

FIGURA 9. Sclere aparent albastre

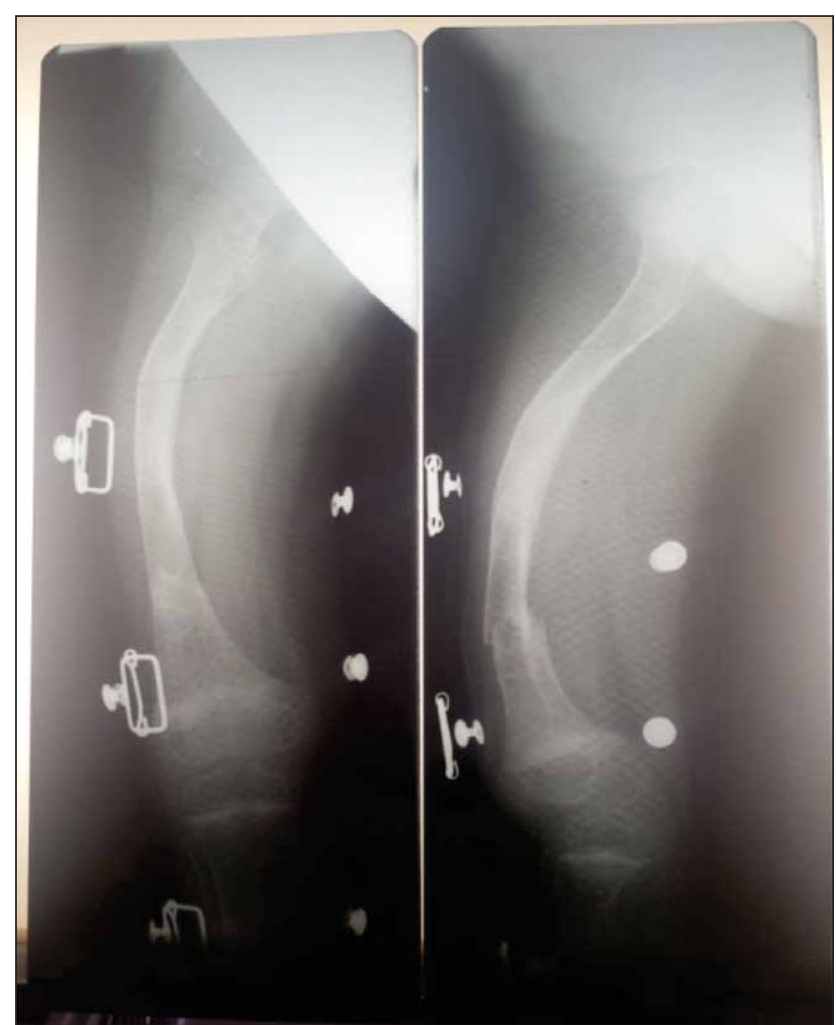

FIGURA 10. Fracturi iterative femur

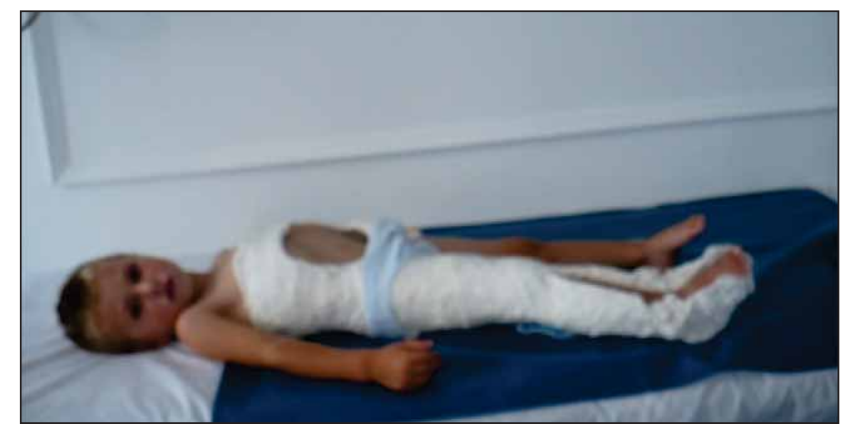

FIGURA 11. Imobilizare gipsată a fracturii de femur

de malformații congenitale, genetice sau tulburări de reproducere. Sarcina a fost supravegheată, lipsită de evenimente, iar pacientul a fost născut natural, în prezentație craniană, la termen, cu o greutate şi talie în limite normale. 

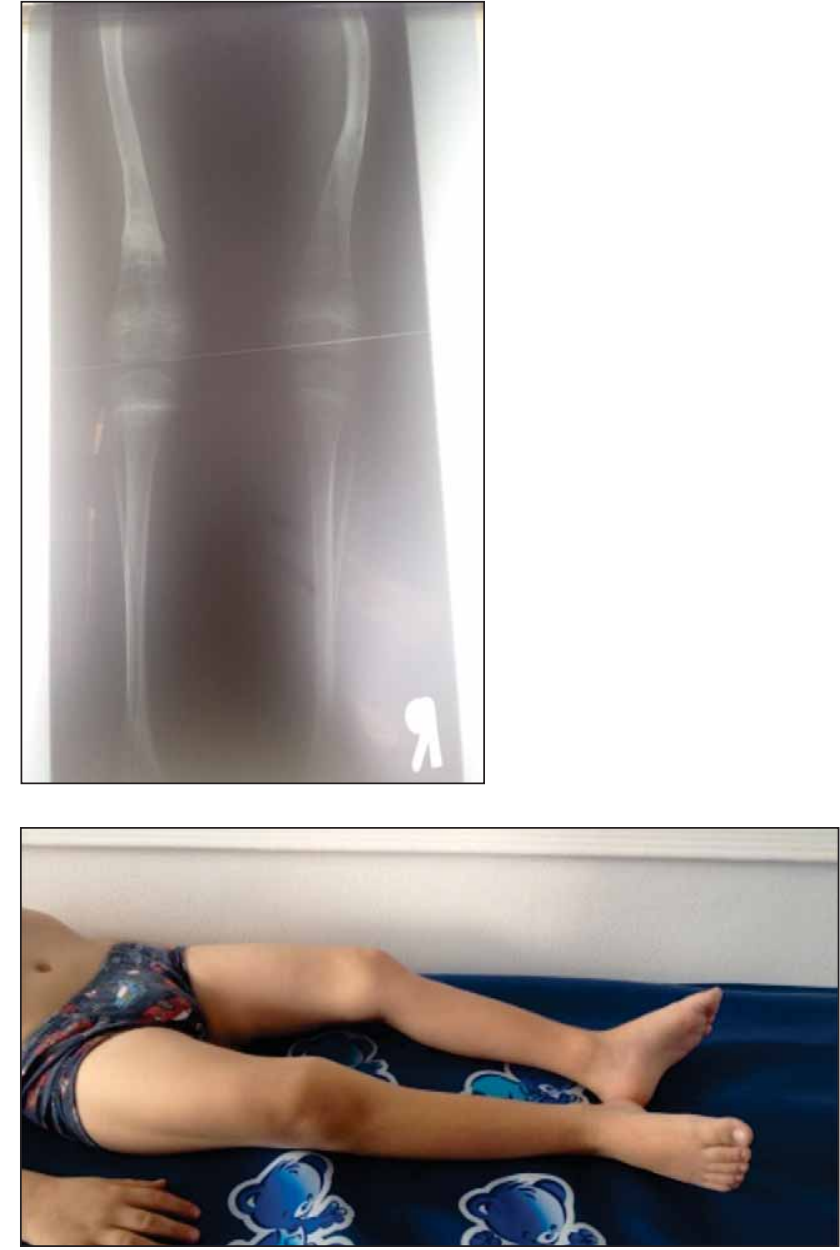

FIGURA 12, 13. Deformare în varum a membrelor inferioare

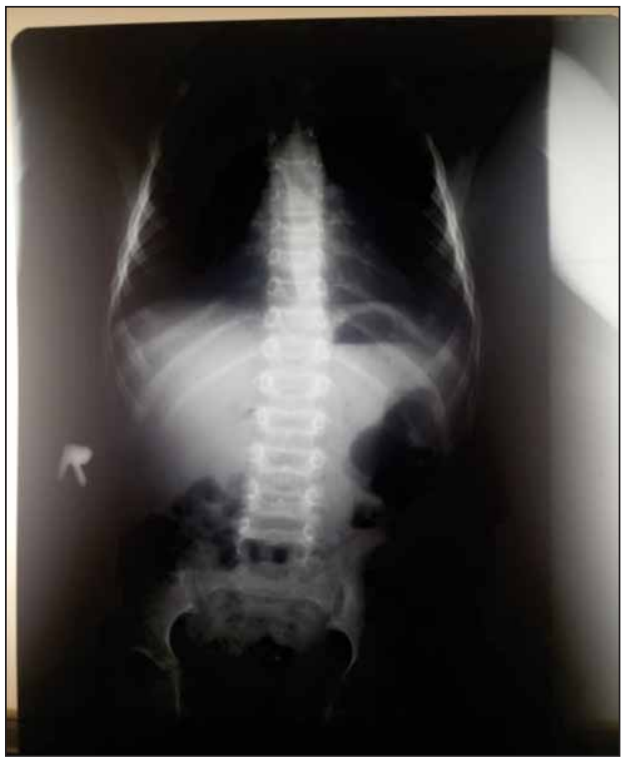

FIGURA 14. Scolioză secundară

\section{INVESTIGAṬII}

Ca total $-10,50 \mathrm{mg} / \mathrm{dl}(\mathrm{VN}: 8,4-11), \mathrm{Ca}$ ionic $4,56 \mathrm{mg} / \mathrm{dl}$ (VN:4,3-5,3), P - 4,62 mg/dl, FA $230 \mathrm{U} / \mathrm{L}, \mathrm{CPK}-200 \mathrm{U} / \mathrm{L}, \mathrm{LDH}-446 \mathrm{U} / \mathrm{L}$ (VN: 300-600), PTH seric - 18 pg/ml (15-65), TGP-13
U/L (VN: 5-38), TGO-22U/L (VN: 5-35), uree - 23 $\mathrm{mg} / \mathrm{dl}$, clearance creatinină $-64,54 \mathrm{ml} / \mathrm{min}(\mathrm{VN}$ : 75-125), calciurie - 35,87 mg/24h (VN: 100-320), creatinina urinară: $49 \mathrm{mg} / \mathrm{dl}$ (VN: 90-300), fosfor urinar: $283 \mathrm{mg} / 24 \mathrm{~h}$ (400-1300), glicemie - $90 \mathrm{mg} /$ dl, IgG, IgA, IgM - valori normale; osteocalcin $25 \mathrm{ng} / \mathrm{ml}$ (24-70), test boli lizozomale pentru boala Gaucher - negativ, timpanograma, EKG - aspect normal, ecocardiografie - defect septal atrial ostium secundum şi coarctație largă de aortă; osteodensitometrie scor Z-1,7 la membrele inferioare, scor Z-0,6 la membrele superioare. Examenul genetic a stabilit diagnosticul de osteogenesis imperfecta tip I.

Până în prezent, la vârsta de 6 ani, pacientul a avut un număr total de 13 fracturi, 12 fracturi femurale şi o fractură de peroneu. Tratament - acid nerindronic, $2 \mathrm{mg} / \mathrm{kg}$, iv, 1 administrare la interval de 3 luni interval, timp de 2 ani, între vârsta 2-4 ani, care a crescut rezistența osoasă (osteodensitometrie normalizată) şi a redus la minimum rata fracturilor prevenind totodată eventuale deformări severe ale oaselor lungi. Astfel, în perioada tratamentului cu bifosfonați, rata fracturilor a scăzut la 3 vs 7 după întreruperea tratamentului. Ritmul creşterii staturoponderale a fost normal pe toata perioada monitorizată.

\section{DISCUȚII}

Osteogenesis imperfecta (OI) reprezintă o provocare clinică şi de tratament complexă care se exprimă, pe lângă fragilitate osoasă importantă cu susceptibilitate crescută la fracturi, prin tulburări de coagulare a sângelui şi obstrucţia căilor respiratorii, anomalii cardiovasculare şi întârziere în vindecarea plăgilor (4-7). Fizioterapia, reabilitarea şi chirurgia ortopedică sunt pilonii de management în OI. Scopul terapiei multimodale este de a maximiza mobilitatea şi capacităţile funcţionale locomotorii (8) şi, de asemenea, de a asigura o calitate cât mai normală a vieții pentru pacient. În prezent, pentru tratamentul tuturor tipurilor de OI sunt administrați pe scară largă bifosfonați (oral sau iv) şi agenţi antiresorbtivi puternici. Studiile clinice la copil au evidențiat eficacitatea tratamentului $\mathrm{cu}$ bifosfonaţi prin îmbunătățirea densității osoase şi ameliorarea simptomelor clinice (9). Deşi bifosfonații nu sunt un remediu pentru OI, reprezintă un adjuvant eficient pentru terapia acesteia. Bifosfonații au evoluat în timp de la compusul inițial aminobisphosphonates la compuşi de generaţia a 2-a şi a 3-a, cum ar fi pamidronat, alendronat şi risedronat (4). În cazul nostru pacientul 2 a primit 
acid nerindronic, $2 \mathrm{mg} / \mathrm{kg}$, iv, 1 administrare la interval de 3 luni interval, timp de 2 ani. Tolerabilitatea digestivă de bifosfonați pe cale orală este slabă şi experiența cu utilizarea sa la copii este foarte limitată. Pentru a facilita absorbția, care este mai mică de $1 \%$ din doza administrată, bifosfonații trebuie administraţi în condiții de repaus alimentar cu o cantitate suficientă de apă (10). În prezent, există două opțiuni farmacologice pentru creşterea masei osoase: creşterea activității osteoblastice cu analogi ai hormonului paratiroidian sau scăderea activităţii osteoclastice cu bifosfonaţi (11). Experienţa cu bifosfonaţi la copii este limitată, deşi există un număr tot mai mare de publicații care prezintă utilitatea lor în mai multe boli metabolice cu impact osos inclusiv OI, prin faptul că bifosfonați sunt stocaţi şi activitatea biologică are efect cel puțin 2 ani după întreruperea tratamentului prin îmbunătăţirea densităţii minerale osoase, a mobilitații, reducerea incidenței fracturilor şi implicit a durerii osoase cronice, precum şi a markerilor biochimici ai resorbției osoase. Efectele adverse sunt limitate față de adult în cele mai multe cazuri în primele 1-3 zile de la iniţierea tratamentului, se semnalează febră, stare generală influențată, durere abdominală, vărsături, durere musculo-scheletală. Hipofosfatemia asimptomatică, hipomagnezemia şi hipocalcemia care cresc riscul de tetanie sunt rare şi pot fi prevenite prin suplimentarea cu calciu şi vitamina D (12). În cazul nostru tratamentul a fost bine tolerat, nu au fost detectate efecte biologice sau clinice secundare. În prezent în România nu sunt disponibile formule de bifosfonați cu administrare la vârsta pediatrică.

\section{CONCLUZII}

Asocierea tratamentului cu bifosfonați la bolnavii cu vârstă pediatrică diagnosticaţi cu OI reprezintă o opțiune terapeutică eficientă demonstrată de ameliorarea ratei fracturilor, a densității osoase şi implicit a calităţii vieții acestora. 